\title{
Assessing the Effectiveness of a Practice Improvement Project to Reduce Falls after Discharge from an Inpatient Rehabilitation Facility
}

\author{
Jun Zhang, Jamal Khan, Claudia Echaide, Karen Imbrosciano-Kemper, Michael Scicchitano, \\ Jennifer Semel
}

St Charles Hospital, Port Jefferson, NY, USA

Email: zhang@alum.bu.edu

How to cite this paper: Zhang, J., Khan, J., Echaide, C., Imbrosciano-Kemper, K., Scicchitano, M. and Semel, J. (2018) Assessing the Effectiveness of a Practice Improvement Project to Reduce Falls after Discharge from an Inpatient Rehabilitation Facility. Open Journal of Therapy and Rehabilitation, 6, 65-75.

https://doi.org/10.4236/ojtr.2018.62006

Received: April 9, 2018

Accepted: May 27, 2018

Published: May 30, 2018

Copyright $(\odot) 2018$ by authors and Scientific Research Publishing Inc. This work is licensed under the Creative Commons Attribution International License (CC BY 4.0).

http://creativecommons.org/licenses/by/4.0/

\begin{abstract}
Objective: To undertake a qualitative investigation of Fall Prevention and Home Safety Education Program's efficacy to decrease the risk of falling after discharge from inpatient rehabilitation facility. Design: Structured Telephone interviews. Setting: Inpatient Rehabilitation Facility. Participants: 1317 inpatients from the Rehabilitation Unit. Interventions: The Fall Prevention and Home Safety Education program. Main Outcome Measures: The percentage of patients that fell. Results: Since the inception of the program the fall rate has reduced significantly $\left(\chi^{2}=6.38\right.$; $\left.\mathrm{P}<0.05\right)$, reaching the historical minimum of this facility $(n=1174)$. The percentage of falls dropped $5.6 \%$ in only 11 months and the attendance to the class has been increasing at a steady rate. Conclusions: Implementation of a Fall Prevention and Home Safety Education program significantly reduced the rate of falls in the three months post discharge from acute inpatient rehabilitation.
\end{abstract}

\section{Keywords}

Fall, Inpatient Rehabilitation

\section{Introduction}

According to New York State's Department of Health Bureau of Injury Prevention, falls in older adults are the leading cause of injury related deaths, hospitalizations, and emergency department visits annually. Each year, an average of 900 NYS residents aged 65 years or older die from injuries sustained from a fall, and more than 132,000 fall-related incidents result in injuries requiring hospital 
treatment [1]. This cost reaches approximately 31 billion dollars in Medicare expenses according to the Center for Disease Control and Prevention [2]. Additionally, falls contribute to increased morbidity and decreased functional independence, thus putting those who fall at a higher risk for falling again [3] [4].

Evidence suggests that falls are not random and uncontrollable, they occur in predictable patterns and there are identifiable risk factors which can help prevent these adverse events [1]. The factors that increase a person's risk for falling include both intrinsic (i.e. weakness or poor vision) and extrinsic, those that are related to the person's environment (i.e. tripping hazards, wet floors) [5] [6]. Patients admitted to an acute inpatient rehabilitation facility (IRF) present with an array of impairments such as decreased strength, mobility, endurance, balance, coordination, vision and are consequently at higher risk for falling when they are discharged to home [7]. Studies show that $40 \%$ of patients fall at least once in the six months following discharge and 54\% of these falls result in injury [8].

To address this issue, there is a growing body of literature focused on preventing falls in hospitals and in the community [9]. Fall prevention in hospitals and rehabilitation facilities often focuses on preventing falls within these facilities [10] [11] [12], leaving a gap of awareness and knowledge of the fall risk after discharge. There are many differences between the environment in a hospital and home. Interventions that are feasible and effective in the hospital are often not so at home, for example: call bells, bed alarm and ancillary staff are constantly around in these types of facilities [13] but not after discharge, which is why it is essential to have a targeted approach to fall prevention in the community.

A review including 159 trials on fall prevention in the community concluded that group home bases exercise programs and home safety intervention reduces the rate and the risk of falls [14]. A study on stroke outpatients confirmed that falls in this population were associated with less improvement on functional status post discharge [15], which illustrates the importance of these exercise based programs. Multifactorial assessment of individual intervention reduces the risk of falls but not necessarily the rate, this type of interventions is complex and the factors that contribute to this result are yet to be determined [13] [14]. The Australian Commission on Safety and Quality in Health Care has a helpful set of guidelines to prevent falls in the community setting. These emphasize on implementing prevention strategies and reducing risk of falls after discharge by identifying the patients risk from admission, refer to the proper services and educate patients and caregivers [16]. A fall prevention program was conducted in a hospital in Australia with inpatients from the rehabilitation unit. The intervention consisted of providing the patient educational material to prevent falls following discharge. Results show that the intervention group had more knowledge and perception of risks and self-awareness, they also sought assistance with ADLs, made their own home modifications and participated in the home exercise programs. The final outcome was a reduced fall rate compared to the control group who did not participate in any fall prevention program. There were a total of 5 falls from the intervention group versus 17 falls from the control group [17]. Other studies 
found that cognitively intact patients who received the materials on fall prevention and a personal class by a therapist benefited greatly from this educational program and the fall rate after discharge reduced significantly in this group. On the other hand, patients who are cognitively impaired or patients that received only the materials for the class but not the presentation from the therapist did not exhibit a reduced fall rate after discharge compared to a control group [18].

Our facility has been conducting a post discharge survey for several years. $\mathrm{Pa}$ tients are asked about their functional status as well as their overall experience of care at the inpatient facility. In January of 2015 a new question was added to this survey "Have you sustained a fall since being discharged from the rehabilitation program?" An interdisciplinary group of rehabilitation professionals then reviewed the initial data over a period of six months to find that the rate of falls upon discharge was remarkably elevated, results indicated that falls were reported at a rate of nearly 1 in every 4 patients. Consequently, a fall prevention program was implemented to educate patients and caregivers on risk and factors in order to prevent falls and therefore, reduce their rate. The aim of this study is to test the efficacy of The Fall Prevention and Home Safety Education program implemented at our facility.

\section{Method}

\section{Participants}

The sample used in this study consisted of 1317 inpatients from the Rehabilitation Unit of our facility, which is total surveyed admission between January 2015 and September 2016. From the total sample there were $48.5 \%$ men and $51.5 \%$ women and the average of age was 66.2. The most prevalent diagnosis was cerebrovascular accident (CVA), $30 \%$ of the patients, $12 \%$ had lower extremity fracture and $12 \%$ had brain injury (either traumatic or not traumatic). From our total sample $73.8 \%$ of the patients were discharged home while $18.2 \%$ were discharged to skilled nursing facilities. The remaining $8 \%$ were transferred to the medical service during their stay.

This data was collected from January 2015 to September 2016. The Fall Prevention and Home Safety Education program was implemented in October 2015 and data was collected until September 2016. 387 patients participated in the program since it was implemented.

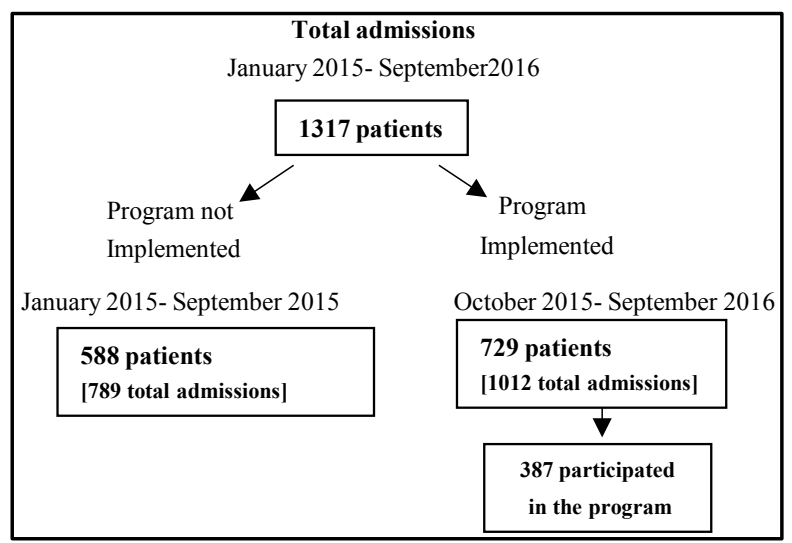




\section{$\underline{\text { Design }}$}

The Fall Prevention and Home Safety Education class offered to inpatients in our inpatient rehabilitation facility, aims to equip patients and caregivers with the knowledge and tools to minimize the risk of falling in the home after discharge. The organization implemented a Fall Prevention Agreement introduced upon admission to engage patients and caregivers in their fall prevention program within the hospital. Classes were initially offered once per week and included multiple patients and their family/caregiver with 1 to 2 facilitators. A formal outline is presented with question and answers to facilitate the understanding of the material. Additionally, written material is provided in the discharge instructions. Patients and families are informed of their increased risk for falling, the impact that a fall may have on their health and mobility, as wells as specific fall prevention interventions to complete in the home to minimize this risk.

Patients are contacted by telephone 3 months after discharge to complete a survey of functional improvement and rate their experience of care, an external agency is contracted to complete the follow up survey (MedTel). In this survey patients are asked: "Have you sustained a fall since being discharged from the rehabilitation program?" Responses are "yes" or " $n o$ ". This is the quality indicator being measured for the study.

This educational intervention was based off a fall prevention program called "Stepping On", developed in Australia. This program is well known internationally for its outcomes in reducing falls in the elderly. "Stepping On" consists of seven classes in which the aim is to promote strategies to enhance self-efficiency amongst attendees. The goal is to take control, explore different coping behaviors and encourage follow through on safety strategies in their everyday lives. The target population is both men and women over 60 years of age who live home alone [19]. Two staff members in the facility are licensed trainers from "Stepping On" and have assisted with the development of the Fall Prevention program at our inpatient rehabilitation facility.

\section{Measurements}

This study will compare the percentage of patients that fell after discharge between January and September 2015, when the fall prevention program was not yet implemented, and the number of patients that fell between October 2015 and September 2016, following implementation of the program. The only variable that is measured is if they have or have not fallen after discharge in a period of three months. A chi square will be performed to see if this difference is statistically significant and consequently evaluate the effectiveness of The Fall Prevention and Home Safety Education program.

\section{Results}

Figure 1 shows the total data $(\mathrm{n}=1317)$ month by month and the percentage of patients that fell at least once after discharge. From January to September 2015 
the program was not implemented and 131 patients fell at least once after discharge from a total of 588 completed surveys, a percentage of $22.9 \%$. After the program was implemented, 387 patients attended the class out of 729 patients that completed a survey 3 months post discharge. The total number of falls after the program was implemented was $103,17.3 \%$ of patients surveyed fell, which indicated a decrease of $5.6 \%$ of the total number of patients that completed the survey. This number is below the facility's historical average. Out of the $387 \mathrm{pa}-$ tients that attended the fall prevention class only 54 patients, $13.4 \%$, reported falls after discharge.

The results show that there is a statistically significant reduction in falls following the introduction of the Fall Prevention and Home Safety Education program $\left(\chi^{2}=6.38 ; \mathrm{P}<0.05\right)$. This information helped the interdisciplinary team to provide education to stakeholders on the value of the class and encouraged an increase in the attendance rate.

The team learned that class attendance was a barrier for the initiative to achieve its greatest impact. Since, the class was expanded to two times per week, the attendance rate increased from $35 \%$ to $48 \%$. Figure 2 shows how the post discharge fall rate decreases slow but steady while the attendance to the class increases rapidly month by month. The numbers represent a percentage of the enrollment to the class out of the total admissions per month. Adding the second class gave patients and their families a greater opportunity to participate in the program. The increase in the attendance rate after offering the class two times per week is statistically different $(p=0.05)$ compared to having the class offered only one time each week.

\section{Discussion}

The Fall Prevention and Home Safety Education program reduced significantly the rate of falls after discharge (5.6\%), 5 months after the program was implemented the facility reached the historical minimum of rate of falls after discharge. These results show the importance of the education and resources provided in the class, enabling the patient and the family to acknowledge the risk factors that lead to falls and consider adaptive equipment and technological options that are more practical and effective in a home environment.

The noted increase in the attendance rate after increasing the frequency of the class, from once a week to twice a week, has provided evidence to support that the implemented change was effective. The rate of patient reported falls has decreased since the launch of the class providing increased incentive for the team to continue to stress the importance of attending the class.

Other programs serving similar patients, as well as those serving various patient populations can adapt this program. Providing the education requires the resources of well-informed and motivated staff for nearly 60 minutes per class as well as accessible space conducive to a group class presentation. Additional resources are required for transportation of patients to and from the class (the amount of staff is dependent on class size). The program outline and required 


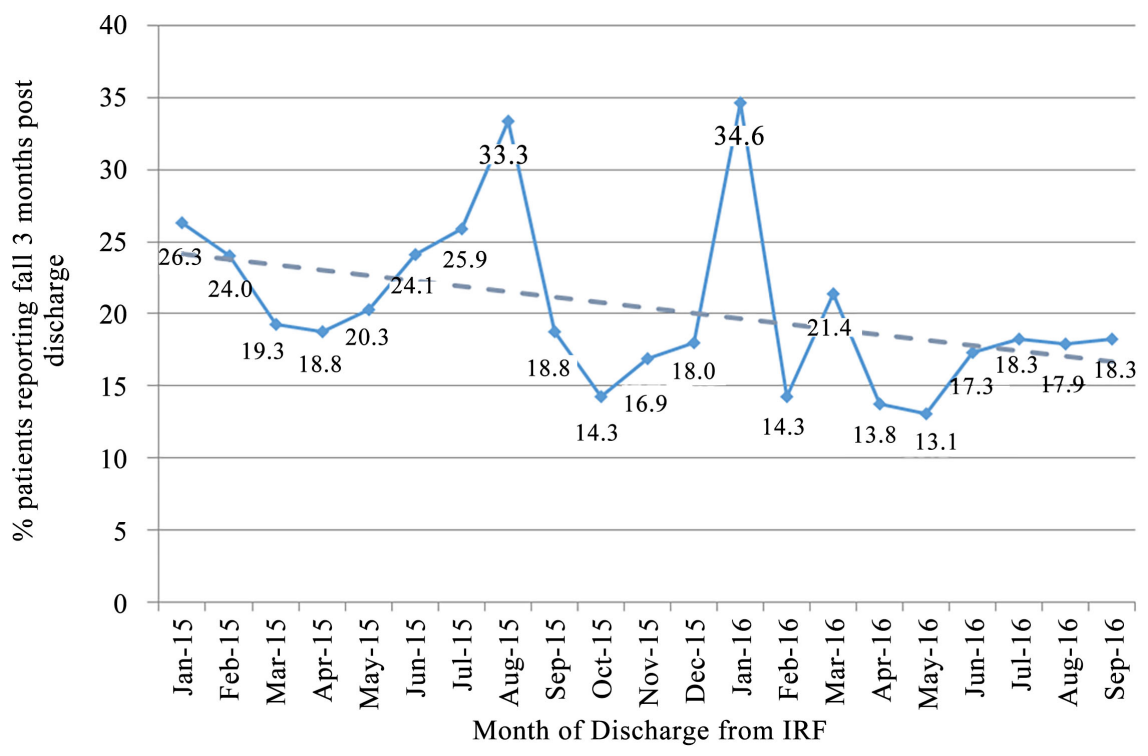

Figure 1. Inpatient rehabilitation facility post discharge patient reported falls 2015-16.

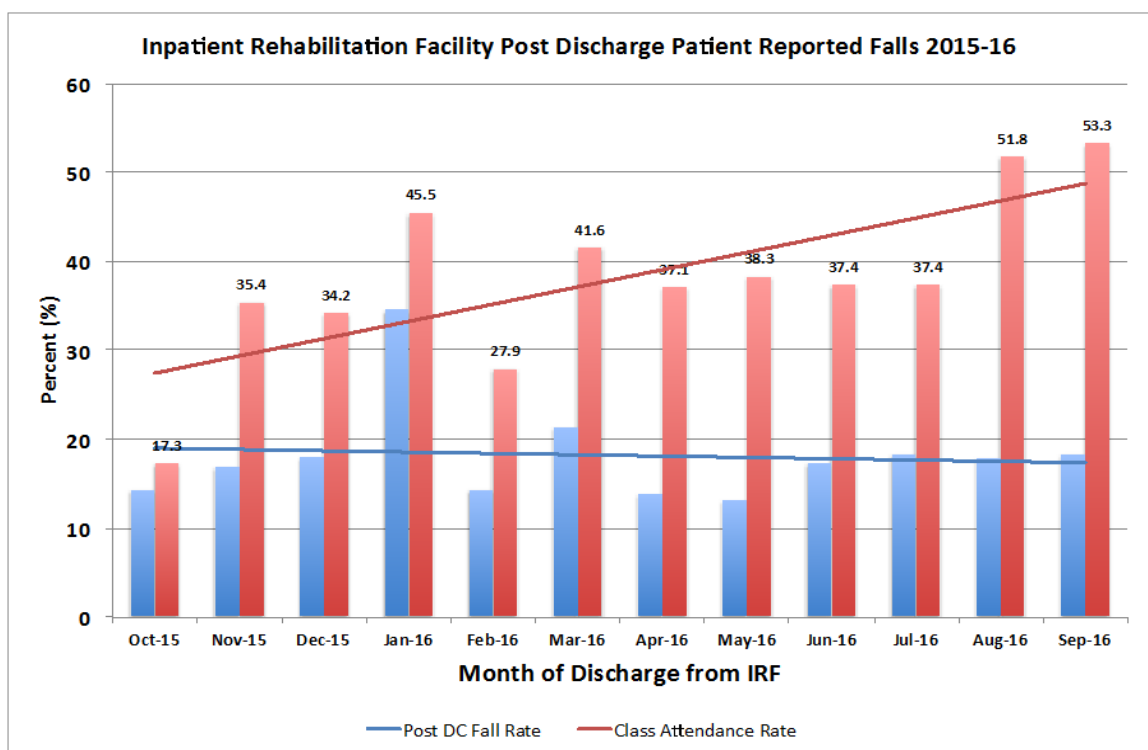

Figure 2. Post discharge patient reported falls 2015-2016.

resources will be presented to another IRF in the organization's health system. It is also proposed that the principles of this education class may be incorporated into this organization's discharge preparation class for post-surgical joint replacement patients. This may also serve to advance the organization's readmission reduction initiative with this population and continues to be aligned with the organization's commitment to patient safety.

Even though the program has presented successful results, we are aware of the limitations. First and most important, no other variables, beside the incidence of falls, were considered. Looking into the data, we noticed that $73.8 \%$ of patients reporting a fall post discharge were discharged to home as opposed to a Skilled Nursing Facility. This may indicate that the patients that are higher functioning 
to return home are at a higher risk for falling, this result was also consistent with Hill, Hoffmann and Haines findings, where $79.7 \%$ of the patients who fell were also living at home as opposed to a nursing home [20]. Another study also found that ambulatory patients post-stroke were more likely to fall post discharge than those with reduced mobility [21].

Knowing the risks of falling after discharge is crucial when educating patients on this topic [22] nevertheless, literature on this issue is scarce. Some studies have found that falls after discharge frequently occur in the winter, most of them indoors (70\%) and 29\% are repeated falls [23], 22.8\% were related to environmental hazards and most were acquired between 6 and 10 am [20]. Diagnosis of the patient and function level upon discharge are the most relevant when assessing the risk of fall, studies show that patients who had severe deficits from a stroke have a lower probability of a fall after discharge, while patients who suffered from left sided hemiplegia/hemiparesis were associated with an increase rate of falls after discharge [23]. Furthermore, decline in mobility, use of assistive device, cognitive impairment or self-report of confusion, also reported higher rates of falls after discharge. Patients that were dependent for their ADLs reported higher rate of falls [24].

The future direction the team has decided to take is precisely to determine predictive factors of increased risk. This information may prove to be valuable in adapting the education model as well as implementation of improved screening methods using standardized testing to target these at higher risk of falling in the community or home.

\section{Conclusion}

Implementation of a Fall Prevention and Home Safety Education program significantly reduced the rate of falls in the three months post discharge from acute inpatient rehabilitation, from $22.9 \%$ to $17.3 \%$. This shows the importance of the education and resources provided in the class. The rate of attendance has also increased from $35 \%$ of the total of admissions to $48 \%$. This is a very positive outcome and the aim of the team is to keep working to determine predictive factors of increased risk. This information may prove to be valuable in adapting the education model as well as implementation of improved screening methods using standardized testing to target these at higher risk of falling in the community or home references of this.

\section{References}

[1] (2017) Injury prevention in New York State. https://www.health.ny.gov/prevention/injury_prevention/

[2] (2016) Cost of Falls among Older Adults. https://www.cdc.gov/homeandrecreationalsafety/falls/fallcost.html

[3] Preventing Falls and Harm from Falls in Older People: Best Practice Guidelines for Australian Community Care (2009) Australian Commission on Safety and Quality in Health Care Canberra Commonwealth of Australia. 
http://www.safetyandquality.gov.au/wp-content/uploads/2012/01/Guidelines-HOSP 1.pdf

[4] Said, C.M., Batchelor, F., Shaw, K. and Blennerhassett, J. (2016) Preparing Patients at High Risk of Falls for Discharge Home after Rehabilitation: Do We Meet the Guidelines? Geriatrics Gerontology International, 16, 570-576. https://doi.org/10.1111/ggi.12511

[5] Tinetti, M.E., Speechley, M. and Ginter, S.F. (1988) Risk Factors for Falls among Elderly Persons Living in the Community. New England Journal of Medicine, 319, 1701-1707. https://doi.org/10.1056/NEJM198812293192604

[6] Graafmans, W., et al. (1996) Falls in the Elderly: A Prospective Study of Risk Factors and Risk Profiles. American Journal of Epidemiology, 143, 1129-1136.

https://doi.org/10.1093/oxfordjournals.aje.a008690

[7] Man-Di Ng, M., Hill, K.D., Batchelor, F. and Burton, E. (2017) Factors Predicting Falls and Mobility Outcomes in Patients with Stroke Returning Home after Rehabilitation Who Are at Risk of Falling. Archives of Physical Medicine and Rehabilitation, 98, 2433-2441. https://doi.org/10.1016/j.apmr.2017.05.018

[8] Hill, A., et al. (2011) Evaluation of the Sustained Effect of Inpatient Falls Prevention Education and Predictors of Falls after Hospital Discharge: Follow-Up to a Randomized Controlled Trial. The Journals of Gerontology: Series A, 66, 1001-1012. https://doi.org/10.1093/gerona/glr085

[9] Thomas, S. and Mackintosh, S. (2014) Use of the Theoretical Domains Framework to Develop an Intervention to Improve Physical Therapist Management of the Risk of Falls after Discharge. Physical Therapy, 94, 1660-1675. https://doi.org/10.2522/ptj.20130412

[10] Tutuarima, J.A., de Haan, R. and Limburg, M. (1993) Number of Nursing Staff and Falls: A Case-Control Study on Falls by Stroke Patients in Acute Care Settings. Journal of Advanced Nursing, 18, 1101-1105. https://doi.org/10.1046/j.1365-2648.1993.18071101.x

[11] Haines, T.P., Bennell, K.L., Osborne, R.H. and Hill, K.D. (2004) Effectiveness of Targeted Falls Prevention Program in Subacute Hospital Setting: Randomized Controlled Trial. BMJ, 328, 676. https://doi.org/10.1136/bmj.328.7441.676

[12] Hoffmann, V.S., Neumann, L., Golgert, S. and Von Renteln-Kruse, W. (2015) Pro-Active Fall-Risk Management is Mandatory to Sustain in Hospital-Fall Prevention in Older Patients-Validation of the LUCAS Fall-Risk Screening in 2,337 Patients. The Journal of Nutrition, Health \& Aging, 19, 1012-1018. https://doi.org/10.1007/s12603-015-0662-1

[13] Cameron, I.D., et al. (2010) Interventions for Preventing Falls in Older People in Nursing Care Facilities and Hospitals. Cochrane Database System Reviews, 1, No. 1. https://doi.org/10.1002/14651858.CD005465.pub2

[14] Gillespie, L.D., et al. (2012) Interventions for Preventing Falls in Older People Living in the Community. Cochrane Database System Reviews, 9, CD007146. https://doi.org/10.1002/14651858.CD007146.pub3

[15] Van der Kooi, E., et al. (2017) Falls Are Associated with Lower Self-Reported Functional Status in Patients after Stroke. Archives of Physical Medicine and Rehabilitation, 98, 2393-2398. https://doi.org/10.1016/j.apmr.2017.05.003

[16] Australian Commission on Safety and Quality in Health Care. Preventing Falls and Harm from Falls: Best Practice Guidelines for Australian Hospitals (2009) Canberra, New South Wales, Australia: Australian Commission on Safety and Quality in Health Care. 
[17] Hill, A.M., Etherton-Beer, C. and Haines, T.P. (2013) Tailored Education for Older Patients to Facilitate Engagement in Falls Prevention Strategies after Hospital Discharge-A Pilot Randomized Controlled Trial. PloS One, 8, e63450. https://doi.org/10.1371/journal.pone.0063450

[18] Haines, T.P., et al. (2011) Patient Education to Prevent Falls among Older Hospital Inpatients: A Randomized Controlled Trial. Archives of Internal Medicine, 171, 516-524. https://doi.org/10.1001/archinternmed.2010.444

[19] Clemson, L., et al. (2004) The Effectiveness of a Community-Based Program for Reducing the Incidence of Falls in the Elderly: A Randomized Trial. Journal of the American Geriatrics Society, 52, 1487-1494. https://doi.org/10.1111/j.1532-5415.2004.52411.x

[20] Hill, A.M., Hoffmann, T. and Haines, T.P. (2013) Circumstances of Falls and Falls-Related Injuries in a Cohort of Older Patients Following Hospital Discharge. Clinical Interventions in Aging, 8, 765-774. https://doi.org/10.2147/CIA.S45891

[21] Xu, T., et al. (2017) Risk Factors for Falls in Community Stroke Survivors: A Systematic Review and Meta-Analysis. Archives of Physical Medicine and Rehabilitation, 99, 563-573.e5.

[22] Rice, L.A., Ousley, C. and Sosnoff, J.J. (2015) A Systematic Review of Risk Factors Associated with Accidental Falls, Outcome Measures and Interventions to Manage Fall Risk in Non-Ambulatory Adults. Disability and Rehabilitation, 37, 1697-1705. https://doi.org/10.3109/09638288.2014.976718

[23] Lim, J.Y., Jung, S.H., Kim, W.S. and Paik, N.J. (2012) Incidence and Risk Factors of Poststroke Falls after Discharge from Inpatient Rehabilitation. PM\&R, 4, 945-953. https://doi.org/10.1016/j.pmrj.2012.07.005

[24] Mahoney, J., Sager, M., Dunham, N.C. and Johnson, J. (1994) Risk of Falls after Hospital Discharge. Journal of the American Geriatrics Society, 42, 269-274. https://doi.org/10.1111/j.1532-5415.1994.tb01750.x 


\section{Abbreviations}

CVA: cerebrovascular accident.

IRF: inpatient rehabilitation facility.

\section{Appendix 1. Fall Prevention Program Outline}

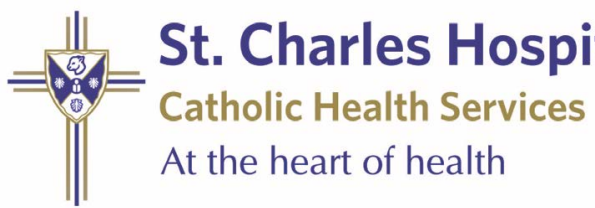

\section{St. Charles Hospital Inpatient Rehabilitation Department Fall Prevention Home Safety Checklist}

There are many things that you and your family can do to help prevent accidents in your home. Before your family member comes home from the rehabilitation center, use the following checklist to help make your home a safer place.

\section{EXTERIOR}

$\square \quad$ Are step surfaces non-skid?

$\square$ Are step edges visibly marked to avoid tripping?

$\square$ Are steps in good condition?

$\square$ Are stairway handrails present and securely fastened?

$\square$ Are walkways free of objects that could be tripped over?

$\square$ Is there sufficient outdoor lighting for walking safely at night?

\section{INTERIOR}

$\square$ Are lights bright enough to compensate for limited vision?

$\square$ Are light switches accessible to persons before entering the room?

$\square$ Are lights glare free?

$\square$ Are stairways adequately lit? Are there light switches at the top and bottom of the stairway?

$\square$ Are stairway handrails present and securely fastened?

$\square$ Are step edges clearly visible and slip resistant?

$\square$ Are throw rugs secured with non-skid backing or are edges taped or tacked down?

$\square$ Can some throw rugs be eliminated? It would be best to get rid of throw rugs!

$\square$ Are carpets in good condition? Are there any loose threads that can catch toes or walkers?

$\square$ Are rooms uncluttered to permit unobstructed mobility?

$\square$ Are chairs throughout the home strong enough to provide support during transfers?

$\square$ Are armrests present on chairs to provided assistance while transferring?

$\square$ Are kitchen and dining room tables secure enough to provide support if leaned on?

$\square$ Do low lying objects (coffee tables or step stools) present a tripping hazard?

$\square$ Are telephones accessible?

$\square$ Are shoes and other clothing properly fitted to prevent tripping? 


\section{KITCHEN}

$\square$ Are storage areas easily reached without having to stand on tiptoe or a chair?

$\square$ Are linoleum floors slippery?

口 Is there a non-skid mat securely placed in front of the sink to soak up spilled water?

$\square$ Are chairs free of wheels? Equipped with arm rests? Proper height to allow for safe transfers?

$\square$ Are step stools strong enough to provide support? Are stool treads in good condition and slip resistant?

$\square$ Are there duplicates of medication in the refrigerator? (Misuse of medications may contribute to falls)

\section{BATHROOM}

$\square$ Are doors wide enough to provide unobstructed access with or without a walker or other device?

$\square$ Do door thresholds present a tripping hazard?

$\square$ Are floors slippery, especially when wet?

$\square$ Are there unsecured throw rugs? (full bath carpeting is an alternative)

$\square$ Are skid-proof strips or mats in the tub or shower?

$\square$ Are tub and toilet grab bars available? Are grab bars securely fastened in wall studs?

$\square$ Are toilets low in height? Is an elevated toilet seat available to assist in toilet transfers?

$\square \quad$ Is there sufficient, accessible and glare-free light?

\section{BEDROOM}

$\square$ Is there adequate and accessible lighting? Are night lights and bedside lamps available for nighttime bathroom trips?

$\square \quad$ Is the pathway from the bed to the bathroom free of obstructions?

$\square$ Are beds of appropriate height to allow for safe transfers on and off?

$\square$ Are floors covered with a nonskid surface and free of obstacles that could be tripped over?

Can person reach objects from closet shelves without standing on tiptoe or on a chair? 